\title{
Alterations in the Levels of Circulating and Endothelial Progenitor Cells Levels in Young Adults with Type I Diabetes: A 2-Year Follow-Up from the Observational METRO Study
}

This article was published in the following Dove Press journal:

Diabetes, Metabolic Syndrome and Obesity: Targets and Therapy

Miriam Longo
Lorenzo Scappaticcio'
Giuseppe Bellastella $\mathbb{D}^{1,2}$
Vlenia Pernice' $^{\prime}$
Paolo Cirillo'
Antonietta Maio'
Filomena Castaldo
Dario Giugliano $\mathbb{D}^{1,2}$
Katherine Esposito $\mathbb{D}^{1,3}$
Maria Ida Maiorino $\mathbb{D}^{1,2}$
On Behalf of the METRO Study
Group

'Department of Advanced Medical and Surgical Sciences, University of Campania "Luigi Vanvitelli", Naples 80138, Italy; ${ }^{2}$ Unit of Endocrinology and Metabolic Diseases, University of Campania "Luigi Vanvitelli”, Naples 80I38, Italy; ${ }^{3}$ Unit of Diabetes, University of Campania "Luigi Vanvitelli”, Naples 80138, Italy
Correspondence: Maria Ida Maiorino Unit of Endocrinology and Metabolic Diseases, Department of Advanced Medical and Surgical Sciences, University of Campania "Luigi Vanvitelli", Piazza Miraglia 2, Naples 80138 , Italy

Tel +390815665289

$\mathrm{Fax}+390815665032$

Email mariaida.maiorino@unicampania.it
Purpose: Type 1 diabetes is associated with high risk of cardiovascular disease (CVD). Reduced levels of circulating progenitor cells (CPCs) and endothelial progenitor cells (EPCs) have been indicated as a risk factor for adverse cardiovascular outcomes and death in people at high cardiovascular risk. The aim of the present study was to evaluate the change in CPCs and EPCs levels in a population of young type 1 diabetic patients treated with intensive insulin regimen over a period of 2 years.

Patients and Methods: A total of 204 type 1 diabetic patients, of whom 84 treated with insulin pump (CSII) and 120 with multiple daily insulin injections (MDI), completed a 2-year follow-up. Clinical measurements, including the indices of glycemic control and glucose variability, were collected at baseline and after 2 years. Both CPC and EPC cell count were assessed by flow cytometry.

Results: Mean age of participants was 24.5 years and mean diabetes duration was 13.6 years. After 2 years, we found a significant reduction of HbA1c $(-0.3 \%$ versus baseline, $\mathrm{P}<0.001)$, associated with decrease in mean amplitude of glucose excursion (MAGE) $(-0.5 \mathrm{mmol} / \mathrm{L}$ versus baseline, $\mathrm{P}<0.001)$, continuous overall net glycemic action (CONGA) $(-0.2 \mathrm{mmol} / \mathrm{L}$ versus baseline, $\mathrm{P}=0.006)$, and blood glucose standard deviation (BGSD) $(-0.2 \mathrm{mmol} / \mathrm{L}$ versus baseline, $\mathrm{P}<0.001)$. The number of all EPCs phenotypes, but not CPC cell count, significantly raised up in the entire population, with higher increase in CSII group. MAGE resulted as an independent predictor for increased levels of both $\mathrm{CD} 34+(\mathrm{P}=0.020)$ and $\mathrm{CD} 34+\mathrm{KDR}+(\mathrm{P}=0.004)$ cell count in the whole population.

Conclusion: Over a 2-year follow-up, young type 1 diabetic patients showed an increase in circulating EPCs levels, which was higher in patients with CSII. Glucose variability resulted as an independent predictor of the raised levels of EPCs in this selected population.

Keywords: endothelial progenitor cells, circulating progenitor cells, glucose variability, type 1 diabetes, CSII, MDI

\section{Introduction}

Type 1 diabetes is characterized by macrovascular (coronary artery diseases) and microvascular (neuropathy, retinopathy, nephropathy) complications. Cardiovascular disease (CVD) represents the leading cause of morbidity and mortality for patients with type 1 diabetes, and contributes to the reported 8-13-year decrease in lifespan for patients with type 1 diabetes. ${ }^{1,2}$ The main contribution to the increased cardiovascular risk might be identified in poor glycemic control, although the relationship between 
HbAlc concentrations and macrovascular complications is less convincing in type 1 diabetes than for microvascular complications. ${ }^{3}$ Besides the traditional cardiovascular risk factors (hyperglycemia, hypertension, dyslipidemia), other mechanisms potentially involved in increasing cardiovascular risk of individuals with type 1 diabetes might be glucose variability ${ }^{4}$ and defective mechanisms of vascular repair. ${ }^{5}$

Diabetes mellitus is characterized by an impaired differentiation and recruitment of adult pluripotent cells to sites of vascular damage. ${ }^{6,7}$ Both circulating progenitor cells (CPCs) and endothelial progenitor cells (EPCs) represent an integral component of cardiovascular homeostasis participating in the process of endothelial repair after vascular injury. ${ }^{8,9}$ Reduced circulating levels of EPCs have been indicated as a risk factor for adverse cardiovascular outcomes and death in people at high cardiovascular risk, including diabetic patients. ${ }^{4}$ Recent studies showed lower circulating levels of EPCs in young adults or children with type 1 diabetes, as compared with healthy controls. ${ }^{10,11}$ Moreover, evidence from observational studies showed that reduced baseline level of CPCs/EPCs was associated with a significant increased risk of cardiovascular events, all-cause death, and onset/progression of microangiopathy. ${ }^{12}$

No previous studies investigated the change in both CPC and EPCs levels in prospective studies of adults with type 1 diabetes. There is evidence of an EPC increase in children with type 1 diabetes with the most favorable HbA1c lowering during a 1-year follow-up..$^{13}$ Moreover, along 8-weeks intervention with metformin, there was an improvement of circulating EPC levels in 23 type 1 diabetic patients without overt CVD. ${ }^{14}$ Furthermore, in a longitudinal study of 106 type 1 diabetic patients, the use of insulin pump for six months resulted in increased levels of EPCs, which was associated with a reduction of glucose variability. ${ }^{15}$ We hypothesized that glucose variability might be associated longitudinally with change in circulating levels of stem/progenitor cells in young adults with type 1 diabetes, thus contributing to raise up cardiovascular risk at such age. Herein, we assessed the levels of both CPCs and EPCs in young adults with type 1 diabetes treated with intensive insulin regimen over a 2-year follow-up. To this purpose, we used the Management and Technology for Transition (METRO) study, a longitudinal observational study of type 1 diabetic patients transitioned to the adult care center.

\section{Materials and Methods}

\section{Study Design and Participants}

The study was approved by the Medical Ethics Committee of University of Campania "Luigi Vanvitelli" (protocol number 33_24.01.2014) and complies with the Declaration of Helsinki and the International Conference on Harmonization/Good Clinical Practice Guidelines. All participants signed an informed consent before enrollment. The protocol of the study has been described elsewhere. ${ }^{15,16}$ Briefly, young adults with type 1 diabetes in transition from the Pediatric Clinic considered eligible for the study were enrolled at Diabetes Unit of University of Campania "Luigi Vanvitelli" (Naples, Italy). Inclusion criteria were: type 1 diabetes, age between 18 and 30 years, duration of diabetes $>1$ year, persistent poor glycemic control $(\geq 7.5 \%$ ), multiple daily injections of insulin (MDI) or continuous subcutaneous insulin infusion (CSII) therapy. We considered as exclusion criteria type 2 diabetes, pregnancy or planning to become pregnant in the next 2 years, inability to use the study devices, history of diabetic ketoacidosis, history of severe chronic diseases, or drug or alcohol abuse.

Three hundred and two patients were consecutively screened at our Diabetes Unit (Supplementary Figure 1). Among these, only 260 patients were considered eligible for the participation of the study according to inclusion and exclusion criteria; 56 patients were excluded from the study, as 13 women got pregnant and the other 43 patients did not complete the follow-up.

\section{Study Measurements}

All participants in the study underwent blinded Dexcom G4 CGM system (Dexcom, Inc., San Diego, CA) for 14 days at basal evaluation, and after 24 months. Glycemic readings from CGM were entered in the EasyGV(C) software (www. phc.ox.ac.uk/research/diabetes/software/easygv/) to calculate the following glucose variability indices: the mean amplitude of glucose excursions (MAGE), the blood glucose standard deviation (BGSD), and the continuous overall net glycemic action (CONGA-2 h).

All patients underwent a full physical examination to assess weight and height, body mass index (BMI), and blood pressure. Fasting plasma glucose, HbAlc, total and high-density lipoprotein cholesterol, and triglycerides, were measured at the hospital's chemistry laboratory. Low-density lipoprotein cholesterol was calculated according to Friedwald. Total insulin dose was recorded through the entire follow-up and expressed as units per kilograms of body weight. All measurements were collected at baseline and after 2 years. 


\section{Assessment of Circulating Levels of CPCs and EPCs}

Assessment of circulating levels of EPCs and CPCs was performed on fresh blood samples collected in citrate-tubes after the overnight fasting, respectively, at baseline and at the end of the follow-up. Peripheral blood cells were analyzed for the expression of surface antigens $\mathrm{CD} 34^{+}, \mathrm{KDR}^{+}$, and $\mathrm{CD} 133^{+}$by direct flow cytometry, in order to assess six different cell phenotypes. Quantitative analysis was performed on a BD FACSCalibur cytometer (Becton-Dickinson) and 1,000,000 cells were acquired in each sample. Granulocytes were excluded using a morphological gate. $\mathrm{CD} 34^{+} \mathrm{CD} 133^{+}$cells were defined as cells presenting the two antigens in the mononuclear cell population. Then, we gated $\mathrm{CD} 34^{+}$or $\mathrm{CD} 133^{+}$ peripheral blood cells in the mononuclear cell fraction and examined the resulting population for the dual expression of KDR. Cells presenting all the three antigens were identified by the simultaneous expression of KDR and CD133 in the CD $34^{+}$ gate. We defined CPCs the cellular pool expressing the markers of stem cells $\left(\mathrm{CD} 34^{+}, \mathrm{CD} 133^{+}\right.$and $\mathrm{CD} 34^{+} \mathrm{CD} 133^{+}$cells), and
EPCs all cells presenting KDR that suggests their commitment toward the endothelial line $\left(\mathrm{CD} 34^{+} \mathrm{KDR}^{+}, \mathrm{CD} 133^{+} \mathrm{KDR}^{+}\right.$and $\mathrm{CD} 34^{+} \mathrm{KDR}^{+} \mathrm{CD} 133^{+}$cells). Data were processed with the use of the Macintosh CELLQuest software program (BectonDickinson). Both CPC and EPC count were expressed as the number of cells per $10^{6}$.

\section{Statistical Analysis}

The sample size calculation was based on the variation of circulating $\mathrm{CD} 34^{+} \mathrm{KDR}^{+} \mathrm{CD} 133^{+}$cells, which are the rarest events among both CPCs and EPCs: ${ }^{12}$ assuming an $\alpha$ level of $0.05 \%$ and $90 \%$ power, the required number of patients to observe a $\mathrm{CD} 34^{+} \mathrm{KDR}^{+} \mathrm{CD} 133^{+}$difference of 5 (standard deviation 10) within the cohort is 45 . Descriptive statistics were used for demographic and baseline clinical characteristics of all participants in the study. Comparisons of baseline data between the patients' groups were performed by Student's $t$ test or Mann-Whitney Rank Sum test, depending on the normality of sample distribution. The $\chi^{2}$ test was used for comparing dichotomous variables.

Table I Baseline Characteristics of Participants in the Study

\begin{tabular}{|c|c|c|c|c|}
\hline & All Patients $(n=204)$ & CSII $(n=84)$ & MDI $(n=120)$ & $\mathbf{P}$ \\
\hline Age, years & $24.5 \pm 2.7$ & $24.8 \pm 2.7$ & $24.4 \pm 2.8$ & 0.25 \\
\hline Diabetes duration, year & $13.6 \pm 4.7$ & $|4| \pm 4.5$. & $13.4 \pm 4.9$ & 0.35 \\
\hline Weight, kg & $69.5 \pm 10.7$ & $70.4 \pm 11.5$ & $68.9 \pm 10.1$ & 0.33 \\
\hline BMI, $\mathrm{kg} / \mathrm{m}^{2}$ & $24.3 \pm 3.1$ & $24.5 \pm 3.1$ & $23.8 \pm 2.9$ & 0.08 \\
\hline Fasting glucose, $\mathrm{mg} / \mathrm{dL}$ & $208.6 \pm 66.9$ & $207.1 \pm 54.4$ & $205.3 \pm 65.4$ & 0.73 \\
\hline $\mathrm{HbAlc}, \%$ & $8.6 \pm 1.1$ & $8.5 \pm 1.0$ & $8.5 \pm 1.1$ & 0.62 \\
\hline $\mathrm{HbAlc}, \mathrm{mmol} / \mathrm{mol}$ & $69 \pm 13$ & $69 \pm 13$ & $69 \pm 11$ & 0.62 \\
\hline Insulin dose, U/kg & $0.69 \pm 0.2$ & $0.69 \pm 0.3$ & $0.69 \pm 0.2$ & 0.98 \\
\hline MAGE, mmol/L & $6.6 \pm 2.1$ & $6.7 \pm 2.1$ & $6.5 \pm 1.6$ & 0.53 \\
\hline CONGA, mmol/L & $6.6 \pm 1.7$ & $6.8 \pm 1.7$ & $6.4 \pm 1.8$ & 0.12 \\
\hline $\mathrm{SD}, \mathrm{mmol} / \mathrm{L}$ & $3.5 \pm 0.8$ & $3.6 \pm 0.8$ & $3.5 \pm 0.7$ & 0.48 \\
\hline \multicolumn{5}{|l|}{ Lipids, mg/dL } \\
\hline Total cholesterol & $165.16 \pm 28.1$ & $167.3 \pm 27.8$ & $163.5 \pm 28.3$ & 0.33 \\
\hline LDL-cholesterol & $91(76-112)$ & $96.5(75-115)$ & $88(76-104)$ & 0.50 \\
\hline HDL-cholesterol & $57.3 \pm 12.8$ & $57.6 \pm 12.4$ & $57.05 \pm 13.1$ & 0.77 \\
\hline Triglycerides & $72(54-89)$ & $74.5(53-97)$ & 71 (54-85) & 0.24 \\
\hline \multicolumn{5}{|l|}{ Blood Pressure, $\mathrm{mmHg}$} \\
\hline SBP & $120(90-140)$ & $120(90-140)$ & $120(90-140)$ & 0.05 \\
\hline DBP & $75(60-90)$ & $77.5(60-85)$ & $70(60-90)$ & 0.66 \\
\hline Microvascular complications, n (\%) & $19(9)$ & $9(10)$ & $10(8)$ & 0.84 \\
\hline \multicolumn{5}{|l|}{ Comorbidities, n (\%) } \\
\hline Thyroiditis & $45(22)$ & $24(28)$ & $21(17)$ & 0.17 \\
\hline Celiac disease & $16(8)$ & $6(7)$ & $10(8)$ & 0.95 \\
\hline Smoke, n (\%) & $5 I(25)$ & $17(20)$ & $34(28)$ & 0.42 \\
\hline
\end{tabular}

Note: Data are expressed as mean \pm standard deviation, or median (interquartile range).

Abbreviations: BMI, body mass index; CSII, continuous subcutaneous insulin infusion; CONGA, continuous overall net glycemic action; DBP, diastolic blood pressure; F, females; M, males; MAGE, mean amplitude glucose excursion; MDI, multiple insulin injections; SD, standard deviation; SBP, systolic blood pressure. 
The changes in all the studied variables $(\Delta)$ were calculated as value at 24 months minus value at baseline. The paired $t$ test and Wilcoxon signed rank test within each patients' group were used to assess changes in the studied variables from baseline to 24 months. Differences in circulating levels of EPCs or CPCs between groups were tested with the Student's $t$ test. Correlation between changes in EPCs count and corresponding changes in clinical variables was assessed by using Spearman's coefficients of correlation. Multiple regression analysis tested the contribution of the independent variables (MAGE, BGSD, fasting glucose, BMI, HbA1c) to the dependent variable (EPCs levels). All analyses were adjusted for potential confounders (age, weight, BMI, gender and smoke), using ANCOVA for the continue variables or a linear regression, as appropriate. P-value $<0.05$ was considered statistically significant. All analyses were performed using SPSS 14.1 (Chicago).

\section{Results}

Among the 204 patients (105 men and 99 women) consecutively recruited from March 2012 and June 2018, 84 were treated with CSII, and 120 were treated with MDI. The basal characteristics of the participants in the study are described in Table 1. Mean age was 24.5 years, mean diabetes duration was 13.6 years, and mean HbA1c level was $8.6 \%$ (69 $\mathrm{mmol} / \mathrm{mol})$. Only 19 patients (9 in CSII group and 10 in MDI group) had microvascular complications. The most frequent comorbidity was thyroiditis in both groups. Neither CSII nor MDI groups differed for demographic and clinical characteristics (Table 1), as well as for the count of all CPC and EPC phenotypes (Supplemental Table S1).

Table 2 summarizes the results obtained after 2 years in the overall population. Compared with baseline, there was a slight but significant decrease of HbA1c (mean change versus baseline $\pm \mathrm{sd},-0.30 \% \pm 1.1 \%, \mathrm{P}<0.001)$, associated with a significant reduction of fasting plasma glucose $(-21.8 \pm 89.7 \mathrm{mg} / \mathrm{dl}, \mathrm{P}<0.001)$ and insulin dose $(-0.13 \pm$ $0.23 \mathrm{U} /$ day, $\mathrm{p}<0.001)$. Moreover, glucose variability decreased as indicated by the significant reduction of MAGE $(-0.5 \pm 2.0 \mathrm{mmol} / \mathrm{L}, \mathrm{P}<0.001), \mathrm{SD}(-0.2 \pm 0.7$, $\mathrm{P}<0.001)$ and CONGA $(-0.2 \pm 1.2, \mathrm{P}=0.006)$. No significant changes were found in weight, BMI, lipids profile and blood pressure after 2 years. When dividing the studied population according to the insulin regimen (Supplemental Table S2), we observed a similar decrease in HbA1c and fasting glucose in both groups. However, compared with baseline, there was a significant reduction of MAGE and SD in the CSII group but not in MDI group; moreover a significant increase of both weight and BMI $(\mathrm{P}=0.004$ and $\mathrm{P}=0.040$, respectively) was found in MDI patients, but

Table 2 Main Outcome at 2 Years in the Overall Population

\begin{tabular}{|c|c|c|c|c|}
\hline \multirow[t]{2}{*}{ Parameters } & \multicolumn{4}{|c|}{ All Patients $(n=204)$} \\
\hline & Baseline & 2 Years & $\Delta$ & $\mathbf{P}$ \\
\hline Weight, kg & $69.5 \pm 10.7$ & $70.1 \pm 11.2$ & $0.63 \pm 10.7$ & 0.056 \\
\hline BMI, $\mathrm{kg} / \mathrm{m}^{2}$ & $24.3 \pm 3.1$ & $24.4 \pm 2.9$ & $0.11 \pm 1.8$ & 0.384 \\
\hline Fasting glucose, $\mathrm{mg} / \mathrm{dL}$ & $208.6 \pm 66.9$ & $186.8 \pm 7 \mid .4$ & $-21.8 \pm 89.7$ & $<0.001$ \\
\hline $\mathrm{HbAlc}, \%$ & $8.6 \pm 1.1$ & $8.2 \pm 1.3$ & $-0.3 \pm 1.1$ & $<0.001$ \\
\hline Insulin dose, U/day & $0.69 \pm 0.21$ & $0.56 \pm 0.22$ & $-0.13 \pm 0.23$ & $<0.001$ \\
\hline MAGE, $\mathrm{mmol} / \mathrm{L}$ & $6.6 \pm 2.1$ & $6.1 \pm 2.1$ & $-0.5 \pm 2.0$ & $<0.001$ \\
\hline CONGA, mmol/L & $6.6 \pm 1.7$ & $6.3 \pm 1.8$ & $-0.2 \pm 1.2$ & 0.006 \\
\hline $\mathrm{SD}, \mathrm{mmol} / \mathrm{L}$ & $3.5 \pm 0.8$ & $3.3 \pm 0.8$ & $-0.2 \pm 0.7$ & $<0.001$ \\
\hline \multicolumn{5}{|l|}{ Lipids, mg/dL } \\
\hline Total cholesterol & $165.2 \pm 28.1$ & $163.5 \pm 27.3$ & $-2.1 \pm 1.2$ & 0.256 \\
\hline LDL-cholesterol & $90.2 \pm 23.5$ & $88.3 \pm 21.7$ & $-1.8 \pm 21.4$ & 0.847 \\
\hline HDL-cholesterol & $57.4 \pm 12.9$ & $56.7 \pm 13.8$ & $-0.7 \pm 12.3$ & 0.691 \\
\hline Triglycerides & $73.5 \pm 21.4$ & $76.8 \pm 22.9$ & $3.1 \pm 21.8$ & $0.48 I$ \\
\hline \multicolumn{5}{|l|}{ Blood Pressure, $\mathrm{mmHg}$} \\
\hline SBP & $120(90-140)$ & $120(80-\mid 40)$ & $0.3 \pm 0.5$ & 0.954 \\
\hline DBP & $75(60-90)$ & $70(60-90)$ & $0.1 \pm 0.6$ & 0.723 \\
\hline
\end{tabular}

Note: Data are expressed as mean \pm standard deviation.

Abbreviations: BMI, body mass index; CONGA, continuous overall net glycemic action; DBP, diastolic blood pressure; MAGE, mean amplitude glucose excursion; SBP, systolic blood pressure; SD, standard deviation. 
not in CSII group. Total insulin doses were also reduced in CSII patients, and remained unchanged in MDI patients. No differences in mean levels of total cholesterol, HDL, LDL, triglycerides, and both systolic and diastolic blood pressure were found in both groups (Supplemental Table S2).

Figure 1 shows the change in circulating levels of both EPCs and CPCs in the overall population after 2 years. Both EPCs and CPCs levels significantly increased at the end of follow-up, except $\mathrm{CD} 34^{+} \mathrm{CD} 133^{+}$circulating levels. Patients with MDI showed a significant increase in $\mathrm{CD}^{+} 4^{+}(\mathrm{P}=0.046)$ and $\mathrm{CD}_{3}{ }^{+} \mathrm{KDR}^{+}(\mathrm{P}=0.034)$, as compared with baseline; excluding $\mathrm{CD}_{3} 4^{+} \mathrm{CD} 133^{+}$, whose number did not change, both CPCs and EPCs cell count increased in patients treated with CSII (Table 3). In the overall population, the change in glucose variability, measured as MAGE and SD, negatively correlated with change in $\mathrm{CD}^{+} 4^{+}, \mathrm{CD} 34^{+} \mathrm{KDR}^{+}$and $\mathrm{CD}^{+} 4^{+} \mathrm{KDR}^{+} \mathrm{CD}_{133^{+}}$cells (Table 4 ), but did not show any correlation with change in the remaining CPCs or EPCs phenotypes (data not shown). No significant associations between changes in the other clinical variables and CPCs or EPCs were found. Multivariable regression analysis adjusted for age, smoking, BMI, and weight identified the reduction of MAGE as an independent predictor for increasing levels of both circulating $\mathrm{CD}^{+} 4^{+}(\beta$-coefficient $=-0.322, \mathrm{P}=0.020)$ and $\mathrm{CD}^{+} \mathrm{KDR}^{+}(\beta$-coefficient $=-0.316, \mathrm{P}=0.004)$ cell count (Table 4).

\section{CD34+}

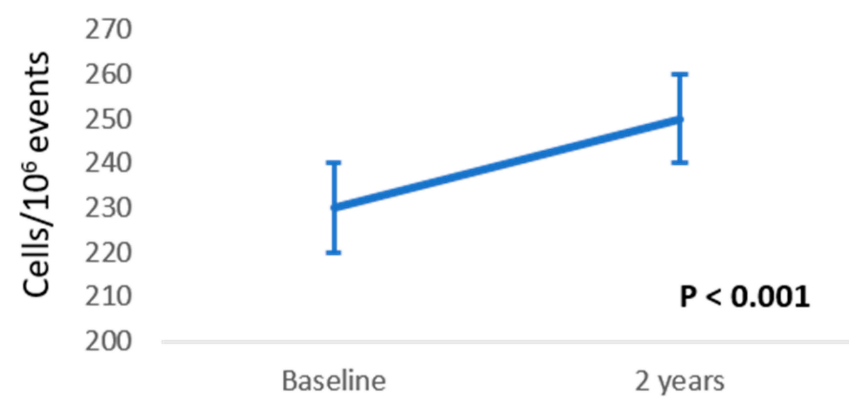

CD34+ KDR+ CD133+

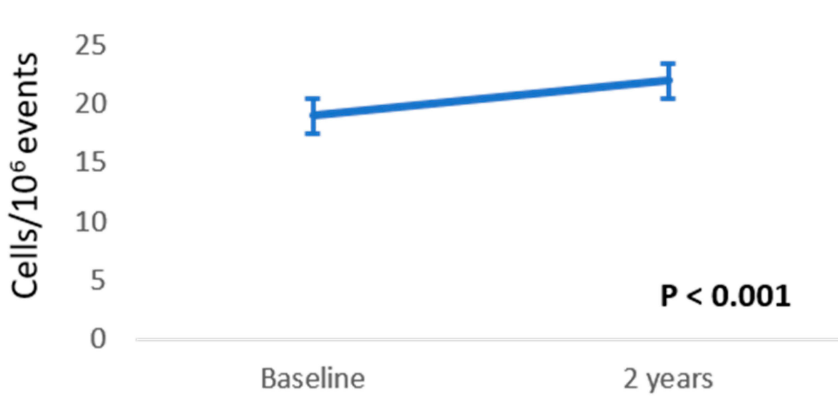

CD133+ KDR+

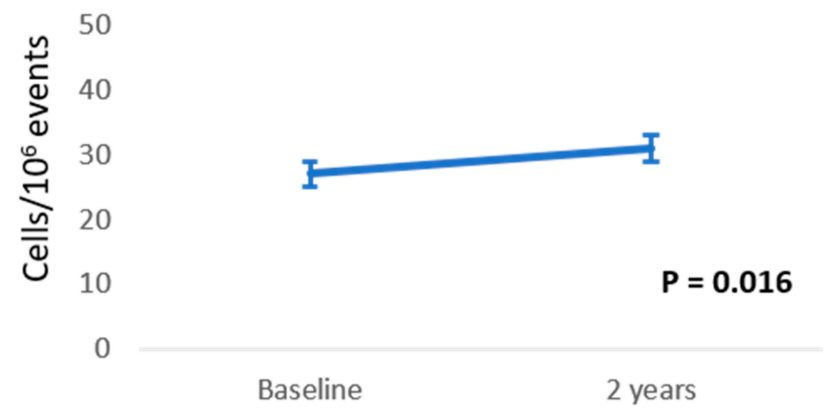

CD133+

$$
\begin{aligned}
& 220 \\
& 210 \\
& 200 \\
& 190 \\
& 180 \\
& 170 \\
& 160 \\
& 150
\end{aligned}
$$

\begin{tabular}{ll} 
& $\mathbf{P}=\mathbf{0 . 0 0 2}$ \\
\hline Baseline & 2 years
\end{tabular}

\section{CD34+ KDR+}

50

20

10

0

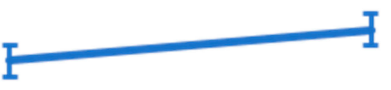

$P<0.001$

Baseline

2 years

\section{CD34+ CD133+}

$P=0.409$

Figure I Change of circulating levels of six phenotypes of EPCs in the overall population over two year-follow-up. 
Table 3 Circulating Levels of Six Phenotypes of EPCs in Type I Diabetic Patients According to Insulin Regimen

\begin{tabular}{|c|c|c|c|c|}
\hline \multirow{4}{*}{$\begin{array}{l}\text { EPCs Phenotypes } \\
\text { CD34 }^{+} \\
\text {Baseline } \\
2 \text { years }\end{array}$} & \multicolumn{2}{|l|}{ CSII $(n=84)$} & \multicolumn{2}{|c|}{ MDI (n = I20) } \\
\hline & & & & \\
\hline & $225(155,324)$ & $<0.001$ & $247(173,279)$ & 0.046 \\
\hline & $256(189,355)$ & & 25 I $(200,273)$ & \\
\hline \multicolumn{5}{|l|}{ CDI $33^{+}$} \\
\hline Baseline & $178(\mid 14,225)$ & 0.005 & $214(138,242)$ & 0.094 \\
\hline 2 years & $199(|4|, 24 I)$ & & $217(158,246)$ & \\
\hline \multicolumn{5}{|l|}{$\mathrm{CD} 34^{+} \mathrm{CD} 133^{+}$} \\
\hline Baseline & $150(95,204)$ & 0.516 & $178(|20,2| 4)$ & 0.630 \\
\hline 2 years & $149(110,199)$ & & $177(130,217)$ & \\
\hline \multicolumn{5}{|l|}{$\mathrm{CD}_{34^{+}}^{\mathrm{KDR}^{+}}$} \\
\hline Baseline & $42(32,49)$ & $<0.001$ & $39(29,44)$ & 0.034 \\
\hline 2 years & $50(40,84)$ & & $40(30,49)$ & \\
\hline \multicolumn{5}{|l|}{$\mathrm{CD} \mid 33^{+} \mathrm{KDR}^{+}$} \\
\hline Baseline & $25(23,35)$ & 0.003 & $31(23,38)$ & 0.525 \\
\hline 2 years & $30(22,50)$ & & $31(22,38)$ & \\
\hline \multicolumn{5}{|l|}{$\mathrm{CD}_{3} 4^{+} \mathrm{KDR}^{+} \mathrm{CD} 133^{+}$} \\
\hline Baseline & $17(14,24)$ & $<0.001$ & $20(14,24)$ & 0.286 \\
\hline 2 years & $25(16,37)$ & & $20(15,26)$ & \\
\hline
\end{tabular}

Notes: Data are expressed as median (interquartile range). EPCs count is expressed as number/ $10^{6}$ events.

Abbreviations: EPCs, endothelial progenitor cells; CSII, continuous subcutaneous insulin infusion; MDI, multiple daily injections.

\section{Discussion}

We showed for the first time an increase in circulating levels of both CPCs and EPCs in young adults with type 1 diabetes over a 2-year follow-up. Interestingly enough, the decrease in MAGE was the only predictive factor explaining the raised EPCs and CPCs number, suggesting that the improvement of glucose variability may positively influence endothelial homeostasis in type 1 diabetes.

Our results are novel, as no previous studies evaluated the change in circulating stem/progenitor cells over time in a population of young adults with type 1 diabetes. The contemporary increase of both CPCs and EPCs suggests an improvement of both bone marrow-regenerative capacity and endothelial repair and angiogenesis. Interestingly, the change in both CPCs and EPCs count was associated with improvement in glucose variability (MAGE and SD), but not with glycemic control estimated as $\mathrm{HbAlc}$ and fasting glucose levels. Moreover, the increase in levels of circulating stem cells seems to be driven by the change observed in patients with CSII who expressed a more pronounced reduction of glucose variability than those treated with MDI. In a previous study of 156 type 1 diabetic children, Hortnhuber et al found a better glycemic
Table 4 Statistical Associations Between Change in Clinical Parameters and Change in Cell Count by Univariate and Multivariate Analysis by Multiple Linear Regression

\begin{tabular}{|l|l|l|l|l|}
\hline Parameter & \multicolumn{2}{l|}{$\begin{array}{l}\text { Univariate } \\
\text { Analysis }\end{array}$} & \multicolumn{2}{l|}{$\begin{array}{l}\text { Analtiple Regression } \\
\text { Analys }\end{array}$} \\
\hline$\Delta$ CD34 $^{+}$ & $\mathbf{r}_{\text {sp }}$ & $\mathbf{P}$ & $\boldsymbol{\beta}$-Coefficient & $\mathbf{P}$ \\
\hline$\Delta$ Weight & 0.100 & 0.365 & 0.098 & 0.459 \\
$\Delta$ BMI & 0.080 & 0.942 & 0.082 & 0.724 \\
$\Delta$ Fasting glucose & 0.044 & 0.685 & 0.039 & 0.287 \\
$\Delta$ HbAlc & -0.145 & 0.063 & -0.128 & 0.142 \\
$\Delta$ MAGE & -0.387 & $<0.001$ & -0.322 & 0.020 \\
$\Delta$ CONGA & -0.098 & 0.346 & -0.041 & 0.836 \\
$\Delta$ SD & -0.259 & 0.017 & -0.152 & 0.078 \\
\hline$\Delta$ CD34 $^{+}$KDR \\
\end{tabular}

Notes: Correlations of EPCs cell count with change in clinical parameters were assessed by Spearman's coefficient $\left(r_{\mathrm{sp}}\right)$. Multiple regression analysis tested the contribution of changes in clinical parameters (independent variables) to the change of EPCs number (dependent variable)

Abbreviations: BMl, body mass index; CONGA, continuous overall net glycemic action; MAGE, mean amplitude glucose excursion; SD, standard deviation.

control associated with an increase in EPC numbers within 1 year, ${ }^{13}$ but the correlation with indices of glucose variability has not been tested.

Among the $\mathrm{CPCs}, \mathrm{CD} 34^{+} \mathrm{CD} 133^{+}$cells were the solely cellular elements which did not raise in our diabetic population. A potential reason for this finding includes their hematopoietic origin, as indicated by the expression of $\mathrm{CD}_{133^{+}}$, that is selectively expressed on hematopoietic stem and progenitor cells. Of note, the unchanged levels of this cellular pool may reflect the rate of extra-medullary hematopoiesis in the spleen, which could provide another peripheral reservoir of hematopoietic stem cells. ${ }^{17}$

Reduction in MAGE, expressing mean differences from glycemic peaks to nadirs, predicted the increase in $\mathrm{CD} 34^{+}$ 
$\mathrm{CPCs}$ and $\mathrm{CD} 34^{+} \mathrm{KDR}^{+}$EPCs in the overall population, suggesting that glucose variability can adversely impact on mechanisms of vascular repair. Among CPCs individual phenotypes, CD34+ cells, together with $\mathrm{CD} 34^{+} \mathrm{CD} 133^{+}$ cells were most frequently associated with cardiovascular outcomes and death. ${ }^{10}$ On the other hand, $\mathrm{CD} 34^{+} \mathrm{KDR}^{+}$ cells alterations were thought to be as markers of endorgan damage in diabetes. ${ }^{18}$ In addition, low circulating levels of $\mathrm{CD} 4^{+} \mathrm{KDR}^{+}$EPCs predicted the occurrence of cardiovascular events and death from cardiovascular causes in patients at high cardiovascular risk. ${ }^{19}$

Evidence from both in vitro and in vivo studies confirmed that oscillating glucose is more deleterious than chronic hyperglycemia in determining endothelial damage, via oxidative stress. ${ }^{18,20}$ Although its role in vascular complications of type 1 diabetes is still being debated, ${ }^{21,22}$ glucose variability results in the presence of excessive glycemic excursions and, in turn, manifest the risk of hyperglycemia or hypoglycemia. Evidence from randomized trials (RCTs) ${ }^{23,24}$ or observational studies $^{11,25}$ reported that CSII therapy is associated with reduced glucose variability in type 1 diabetes, as compared with MDI. Interestingly, in a large observational study of 18,168 type 1 diabetic patients, ${ }^{26}$ a risk reduction of $45 \%$ for fatal coronary heart disease, $42 \%$ for fatal cardiovascular disease, and $27 \%$ for all-cause mortality was found in insulin pump users as compared with patients on MDI, after a mean follow-up of 6.8 years.

Due to the short follow-up period (2 years), we cannot predict whether increased EPCs number in patients with type 1 diabetes would result in a reduced risk of microvascular and macrovascular complications. In the Joslin Medalist study, ${ }^{27}$ the highest EPCs levels were found in Medalists (patients with duration of diabetes of 50 years or longer) without cardiovascular diseases or diabetic microvascular complications, and this was consistent with the unusual survival of these individuals. Moreover, a longitudinal study of 187 patients with type 2 diabetes reported that a reduced baseline level of $\mathrm{CD} 34^{+}$cells predicted microvascular outcomes after a mean follow-up of 3.9 year. $^{28}$

Major strengths of this study include the relatively large number of subjects investigated, the long-term follow-up, the contemporary assessment of CPCs and EPCs, and the comparison between patients treated with MDI or CSII therapy. Due to the observational nature of this study, we cannot make inference regarding cause and effect. Moreover, the potential for residual confounding by uncontrolled co-variate is possible.

\section{Conclusion}

In conclusion, over a 2-year follow-up, young type 1 diabetic patients treated with intensive insulin regimen showed an increase in circulating CPCs and EPCs levels, which correlates with the improvement in glucose variability. Further studies with longer follow-up are needed in order to elucidate whether change in circulating stem cells levels may improve the cardiovascular profile of type 1 diabetic patients.

\section{Acknowledgment}

The authors thank all investigators, study teams and patients for participating in this study. Composition of the METRO Study group. Michela Petrizzo, Maurizio Gicchino, Mariangela Caputo (Unit of Diabetology, University Hospital Luigi Vanvitelli); Carla Carbone, Rosa Di Fraia (Unit of Endocrinology and Metabolic Diseases, University Hospital Luigi Vanvitelli); Annalisa Sarnataro (Department of Advanced Medical and Surgical Sciences, University of Campania "Luigi Vanvitelli"). This research was funded by the Italian Ministry of University and Research (PRIN 2015, protocol 2015ZTT5KB_007).

\section{Disclosure}

The abstract of this paper was presented at the 54th EASD Annual Meeting of the European Association for the Study of Diabetes as a poster presentation with interim findings. The poster's abstract was published in Diabetologia (2018) 61 (Suppl 1): 1. https://doi.org/10.1007/s00125-018-4693-0. Miriam Longo and Lorenzo Scappaticcio shared the first authorship. DG has held lectures for Novo Nordisk, AstraZeneca, Lilly, Mundipharma, Sanofi. KE has held lectures for Novo Nordisk, Lilly, AstraZeneca, Bruno, Mundipharma, Boehringer Ingelheim, Roche, Lifescan, Abbott. MIM has held lectures for Roche, Lifescan and Abbott. All the other authors declare no conflict of interest.

\section{References}

1. Livingstone SJ, Levin D, Looker HC, et al. Estimated life expectancy in a Scottish cohort with type 1 diabetes, 2008-2010. JAMA. 2015;313 (1):37-44. doi:10.1001/jama.2014.16425

2. Huo L, Shaw JE, Wong E, Harding JL, Peeters A, Magliano DJ. Burden of diabetes in Australia: life expectancy and disability-free life expectancy in adults with diabetes. Diabetologia. 2016;59 (7):1437-1445. doi:10.1007/s00125-016-3948-x

3. Maahs DM, Daniels SR, de Ferranti SD, et al. Cardiovascular disease risk factors in youth with diabetes mellitus: a scientific statement from the American Heart Association. Circulation. 2014;130(17):1532-1558. doi:10.1161/CIR.0000000000000094 
4. Gorst C, Kwok CS, Aslam S, et al. Long-term glycemic variability and risk of adverse outcomes: a systematic review and meta-analysis. Diabetes Care. 2015;38(12):2354-2369. doi:10.2337/dc15-1188

5. Saad MI, Abdelkhalek TM, Saleh MM, et al. Insights into the molecular mechanisms of diabetes-induced endothelial dysfunction: focus on oxidative stress and endothelial progenitor cells. Endocrine. 2015;50(3):537-567.

6. Lombardo MF, Iacopino P, Cuzzola M, et al. Type 2 diabetesmellitus impairs the maturation of endothelial progenitor cells and increases the number of circulating endothelial cells in peripheral blood. Cytometry A. 2012;81:856-864. doi:10.1002/cyto.a.22109

7. Loomans CJ, de Koning EJ, Staal FJ, et al. Endothelial progenitor cell dysfunction: a novel concept in the pathogenesis of vascular complications of type 1 diabetes. Diabetes. 2004;53:95-199. doi:10.2337/diabetes.53.1.195

8. Urbich C, Dimmeler S. Endothelial progenitor cells: characterization and role in vascular biology. Circ Res. 2004;95(4):343-353. doi:10.1161/01.RES.0000137877.89448.78

9. Urbich C, Aicher A, Heeschen C, et al. Soluble factors released by endothelial progenitor cells promote migration of endothelial cells and cardiac resident progenitor cells. J Mol Cell Cardiol. 2005;39 (5):733-742. doi:10.1016/j.yjmcc.2005.07.003

10. Rigato M, Avogaro A, Fadini GP. Levels of circulating progenitor cells, cardiovascular outcomes and death: a meta-analysis of prospective observational Studies. Circ Res. 2016;118(12):1930-1939. doi:10.1161/CIRCRESAHA.116.308366

11. Maiorino MI, Della Volpe E, Olita L, Bellastella G, Giugliano D, Esposito K. Glucose variability inversely associates with endothelial progenitor cells in type 1 diabetes. Endocrine. 2015;48(1):342-345. doi:10.1007/s12020-014-0277-z

12. Rigato M, Fadini GP. Circulating stem/progenitor cells as prognostic biomarkers in macro- and microvascular disease: a narrative review of prospective observational studies. Curr Med Chem. 2018;25 (35):4507-4517. doi:10.2174/0929867324666170920154020

13. Hörtenhuber T, Rami-Mehar B, Satler M, et al. Endothelial progenitor cells are related to glycemic control in children with type 1 diabetes over time. Diabetes Care. 2013;36(6):1647-1653. doi:10.2337/dc12-1206

14. Ahmed FW, Rider R, Glanville M, Narayanan K, Razvi S, Weaver JU. Metformin improves circulating endothelial cells and endothelial progenitor cells in type 1 diabetes: MERIT study. Cardiovasc Diabetol. 2016;15(1):116. doi:10.1186/s12933-016-0413-6

15. Maiorino MI, Casciano O, Della Volpe E, Bellastella G, Giugliano D, Esposito K. Reducing glucose variability with continuous subcutaneous insulin infusion increases endothelial progenitor cells in type 1 diabetes: an observational study. Endocrine. 2016;52(2):244-252. doi:10.1007/s12020-015-0686-7

16. Maiorino MI, Bellastella G, Casciano O, et al. The effects of subcutaneous insulin infusion versus multiple insulin injections on glucose variability in young adults with type 1 diabetes: the 2-year follow-up of the observational METRO Study. Diabetes Technol Ther. 2018;20(2):117-126. doi:10.1089/dia.2017.0334
17. Fadini GP, Mehta A, Dhindsa DS, et al. Circulating stem cells and cardiovascular outcomes: from basic science to the clinic. Eur Heart J. 2019. doi:10.1093/eurheartj/ehz923

18. Fadini GP. A reappraisal of the role of circulating (progenitor) cells in the pathobiology of diabetic complications. Diabetologia. 2014;57 (1):4-15. doi:10.1007/s00125-013-3087-6

19. Werner N, Kosiol S, Schiegl T, et al. Circulating endothelial progenitor cells and cardiovascular outcomes. $N$ Engl J Med. 2005;353 (10):999-1007. doi:10.1056/NEJMoa043814

20. Cavalot F. Do data in the literature indicate that glycaemic variability is a clinical problem? Glycaemic variability and vascular complications of diabetes. Diabetes Obes Metab. 2013;15(2):3-8. doi:10.1111/ dom. 12140

21. Lachin JM, Bebu I, Bergenstal RM, et al. Association of glycemic variability in type 1 diabetes with progression of microvascular outcomes in the Diabetes Control and Complications Trial. Diabetes Care. 2017;40(6):777-783. doi:10.2337/dc16-2426

22. Kilpatrick ES, Rigby AS, Atkin SL, et al. Effect of glucose variability on the long-term risk of microvascular complications in type 1 diabetes. Diabetes Care. 2009;32(10):1901-1903. doi:10.2337/dc090109

23. Hirsch IB, Bode BW, Garg S, et al. Continuous subcutaneous insulin infusion (CSII) of insulin aspart versus multiple daily injection of insulin aspart/insulin glargine in type 1 diabetic patients previously treated with CSII. Diabetes Care. 2005;28(3):533-538. doi:10.2337/ diacare.28.3.533

24. Bruttomesso D, Crazzolara D, Maran A, et al. In type 1 diabetic patients with good glycaemic control, blood glucose variability is lower during continuous subcutaneous insulin infusion than during multiple daily injections with insulin glargine. Diabet Med. 2008;25 (3):326-332. doi:10.1111/dme.2008.25.issue-3

25. Maiorino MI, Bellastella G, Petrizzo M, et al. Treatment satisfaction and glycemic control in young type 1 diabetic patients in transition from pediatric health care: CSII versus MDI. Endocrine. 2014;46 (2):256-262. doi:10.1007/s12020-013-0060-6

26. Steineck I, Cederholm J, Eliasson B, et al. Insulin pump therapy, multiple daily injections, and cardiovascular mortality in 18,168 people with type 1 diabetes: observational study. BMJ. 2015;350: h3234. doi:10.1136/bmj.h3234

27. Hernandez SL, Gong JH, Chen L, et al. Characterization of circulating and endothelial progenitor cells in patients with extreme-duration type 1 diabetes. Diabetes Care. 2014;37(8):2193-2201. doi:10.2337/ dc13-2547

28. Rigato M, Bittante C, Albiero M, Avogaro A, Fadini GP. Circulating progenitor cell count predicts microvascular outcomes in type 2 diabetic patients. J Clin Endocrinol Metab. 2015;100(7):2666-2672. doi:10.1210/jc.2015-1687

Diabetes, Metabolic Syndrome and Obesity: Targets and Therapy

\section{Publish your work in this journal}

Diabetes, Metabolic Syndrome and Obesity: Targets and Therapy is an international, peer-reviewed open-access journal committed to the rapid publication of the latest laboratory and clinical findings in the fields of diabetes, metabolic syndrome and obesity research. Original research, review, case reports, hypothesis formation, expert opinion and commentaries are all considered for publication. The manuscript management system is completely online and includes a very quick and fair peer-review system, which is all easy to use. Visit http://www.dovepress.com/testimonials.php to read real quotes from published authors. 